\title{
GESTÃO ESCOLAR NUM PROCESSO EDUCACIONAL MEDIADO PELAS TECNOLOGIAS NA ÁREA CIÊNCIAS DA NATUREZA
}

http://dx.doi.org/10.5902/2318133821972

\author{
Marcia Melchior \\ Universidade Federal de Santa Maria, Brasil. \\ Elena Maria Mallmann \\ Universidade Federal de Santa Maria, Brasil.
}

\begin{abstract}
Resumo
O uso das tecnologias na mediação escolar é um fator principal no processo de ensino e aprendizagem no mundo contemporâneo. Deste modo, o presente artigo tem o objetivo principal mostrar a caracterização e formas de utilização das TIC na área Ciências da Natureza na Escola Estadual de Ensino Médio Guia Lopes, localizada na cidade de Candelária - RS. De natureza qualitativa por meio de estudo de caso, a pesquisa foi realizada com observações diretas realizadas no local e por um questionário enviado via e-mail a oito professores da área pesquisada. A análise apresentou indícios de que houve incentivos por parte da gestão escolar na integração e inserção das TIC.

Palavras-chave: gestão escolar, ciências da natureza e tecnologias.
\end{abstract}

\section{SCHOOL MANAGEMENT IN EDUCATIONAL PROCESS MEDIATED BY TECHNOLOGY IN NATURE SCIENCES AREA}

\section{Abstract}

The use of technology in school mediation is a major factor in the process of teaching and learning in the contemporary world. Thus, this paper has the main objective to show the characteristics and uses of ICT in Natural Sciences area in the State Preparatory High School Guia Lopes located in Candelaria - RS. Qualitative through case study, the research was carried out with direct observations made on site and also by a questionnaire sent via e-mail to eight teachers of the surveyed area. The analysis presented evidence that there were incentives on the part of school management in the integration and inclusion of ICT.

Key-words: school management, natural sciences and technology. 


\section{Introdução}

A $s$ transformações que ocorrem em nossa sociedade passam por diversos segmentos, tais como pelo campo político, social, científico, econômico e educacional. Estas mudanças afetam o comportamento dos indivíduos em todos os aspectos da vida humana. Com a incorporação das tecnologias de informação e comunicação - TIC - aplicadas a educação ocorreram novas probabilidades para a gestão do processo educativo.

Podemos caracterizar as tecnologias de informação como formas de gerar, armazenar, vincular e reproduzir a informação. As tecnologias de comunicação se caracterizam como formas de difundir a informação, incluindo a televisão, o vídeo, as redes de computadores, livros, revistas, rádio. Assim, encontramos as TIC no ambiente escolar pelos recursos tecnológicos como o computador, internet, televisão, rádio, materiais impressos, retroprojetores, projetor de multimídia, filmadora, etc. O desafio em relação às TIC no ambiente escolar é equipar essas tecnologias de forma a atender aos interesses dos estudantes da comunidade de ensino e aprendizagem.

Assim, desde a década de 1990, estão presentes as políticas públicas do governo federal para o uso e presença das tecnologias nas escolas públicas. Elas surgiram a partir da definição das necessidades sociais, com finalidades e objetivos que deverão ser obtidos pelo sistema educacional, e fazem parte de um conjunto de ações para a melhoria do ensino e aprendizagem, tanto dos estudantes, quanto dos professores.

O presente artigo expõe uma tentativa de investigação da ocorrência ou não do uso das tecnologias de informação e comunicação, de forma a potencializar a integração com a gestão escolar de uma escola pública da rede estadual de ensino.

O presente estudo aborda o tema gestão educacional e as tecnologias tendo como objetivo principal a caracterização e as formas de utilização das TIC na área Ciências da Natureza da Escola Estadual de Ensino Médio Guia Lopes, localizada na cidade de Candelária - RS. O problema de pesquisa foi expresso nos seguintes termos: as tecnologias digitais de informação e comunicação são utilizadas no desenvolvimento das ações pedagógicas na área Ciências da Natureza na Escola Estadual de Ensino Médio Guia Lopes?

Diante da amplitude do problema formulado, questões norteadoras foram propostas: Como as tecnologias estão inseridas no projeto político-pedagógico da escola? A gestão escolar está contribuindo para o uso das tecnologias digitais de informação e comunicação nas práticas docentes das disciplinas da área Ciências da Natureza? Que limitações e que possibilidades são percebidas pelos professores para a utilização das tecnologias digitais de informação e comunicação no ensino da área Ciências da Natureza?

\section{Referencial teórico}

Conforme Castells (1999) a revolução tecnológica disseminou-se rapidamente em vinte anos, desde que começou a tomar forma a partir da década de 1970 atingindo seu apogeu na década de 1990 com o progresso das redes de computadores. Moraes (1993) comenta que, no início da década de 1980 , foram realizados seminários para discutir ideias de como inserir projetos-piloto sobre o uso dos computadores para ensino e aprendizagem em universidades. Isso originou, em 1984, ao Projeto Educom, uma 
iniciativa conjunta do Ministério da Educação - MEC com CNPq, Finep, SEI/PR, Ufrgs, UFRJ, UFPE, UFMG e Unicamp. Embora houvesse as dificuldades financeiras este projeto foi o marco principal do processo de geração de base científica e formulação da política nacional de informática educativa.

O Programa Nacional de Informática na Educação - Proinfe - foi criado pelo MEC em 1989. O seu principal objetivo era o de promover o desenvolvimento da informática e seu uso nos sistemas públicos de ensino. Passados alguns anos, em 1997, o MEC criou o Programa Nacional de Tecnologia Educacional - Proinfo - com o intuito de promover o uso pedagógico de tecnologias de informação e comunicação - TIC - na rede pública de ensinos fundamental e médio.

Com relação a todas essas mudanças em relação às novas tecnologias, a gestão educacional enfrentou o desafio de coordenar o pedagógico. A tecnologia é o resultado de transformações e aperfeiçoamentos de uma determinada técnica. Lima (apud Sales 2010, p. 55) afirma que "a técnica tem a ver com arte, criação, intervenção humana e transformação. Tecnologia, em decorrência, refere-se a processo produtivo, criativo e transformativo". Podemos perceber que a inserção das novas tecnologias no processo educacional é um elo para a construção de um novo modelo de ação docente, junto com a construção da significação da função dos gestores educacionais, tendo em vista a utilização das TIC num processo de incorporação aos processos de ensino e aprendizagem. Conforme Sales (2010), "é preciso explorar as possibilidades comunicacionais presentes nas tecnologias de comunicação contemporâneas, compreendendo que elas implicam outra lógica e outra relação que possibilitam novos caminhos e aprendizagens" (p. 61).

É pela colaboração entre gestão escolar e professores que se pode organizar meios, atividades que possam desenvolver melhor o ensino e aprendizagem dos estudantes com a utilização das TIC. Segundo Martins (apud Couto, 2011, p. 124), "na escola o pensar e o recriar para o desenvolvimento de habilidades e ideias criativas possibilitam o sujeito a buscar respostas adequadas, originais e a enfrentar desafios de modo inovador". Porém, podemos perceber que o pensar e fazer em relação à gestão escolar na era digital, não é uma tarefa tão simples, pois esta necessita de atenção e boa vontade em virtude de uma forma inovadora de incentivo no processo de ensino e aprendizagem.

Ao longo dos anos ocorreram políticas públicas de inclusão digital. Os parâmetros curriculares nacionais, em 1998, destacam que os professores precisam ser capazes de conhecer seus estudantes, adequar o processo de ensino e aprendizagem, elaborar atividades que possibilitem o uso das TIC, ou seja, buscar subsídios para um ensino de qualidade que ajudasse na formação de um cidadão crítico. É preciso promover atividades que auxiliem o estudante na compreensão de conceitos, tais como debates, questionamentos, investigação, trabalhos em grupos e o uso das tecnologias. Assim, o estudante passa a entender a ciência como construção histórica sem levar em consideração um ensino fundamentado na memorização de definições e classificações (Brasil, 1998). 
Foi nessas perspectivas que o governo brasileiro desenvolveu políticas públicas de inclusão digital com a finalidade de facilitar o acesso a informação a todos os cidadãos que dela necessite. Com as TIC se almeja proporcionar a inclusão digital. Podemos perceber que as políticas públicas são manifestadas em programas, projetos e ações com o intuito de causar impacto na sociedade.

\section{Ciências da natureza e o uso das tecnologias}

As reformas nos modelos educacionais para o ensino médio ocorreram na segunda metade dos anos 1990. Destacam-se as diretrizes curriculares nacionais para o ensino médio, os parâmetros curriculares nacionais para o ensino médio e os sistemas de avaliação, o Exame Nacional do Ensino Médio - Enem - e o Sistema de Educação Básica - Saeb.

A proposta curricular do ensino médio estabelece a organização do conhecimento escolar em três áreas: Linguagens, Códigos e suas Tecnologias - Língua Portuguesa, Língua Estrangeira Moderna, Educação Física, Artes e Informática -, Ciências da Natureza, Matemática e suas Tecnologias - Biologia, Física, Química e Matemática - e Ciências Humanas e suas Tecnologias - História, Geografia, Filosofia, Antropologia, Política e Sociologia. Essa divisão tem como base reunir em uma mesma área aqueles "conhecimentos que compartilham objetos de estudo e, portanto, que mais facilmente se comunicam" (Brasil, 1999, v. I: p. 20), criando assim, condições para uma prática escolar de interdisciplinaridade.

No que diz respeito às tecnologias o MEC, em seu papel de coordenador das políticas públicas nacionais de educação, traçou diretrizes de fortalecimento de ação pedagógica do professor em sala de aula e da gestão da escola, bem como apontou para implantação de políticas de modernização, como a introdução de inovações tecnológicas no processo de ensino e aprendizagem. Além da modernização, o programa apresenta a intenção de melhorar a qualidade do processo de ensino e aprendizagem por meio da criação de uma nova organização nos ambientes escolares mediante a incorporação adequada das tecnologias (Brasil, 1997a).

\section{Metodologia}

O presente estudo valeu-se de uma pesquisa descritiva de natureza qualitativa com estudo de caso. Utilizou-se como fontes de evidências um questionário com questões abertas e fechadas, projeto político-pedagógico da escola analisada e observações diretas. A observação direta aconteceu pela visitação à Escola Estadual de Ensino Médio Guia Lopes, situada na cidade de Candelária, RS. A escolha da escola ocorreu em virtude da pesquisadora trabalhar na escola e pelo interesse em saber como tecnologias estão inseridas no ambiente escolar. O questionário foi utilizado como coleta de evidências junto a um público específico, que neste caso contou com a participação de oito professores da área Ciências da Natureza da escola. O principal objetivo desta pesquisa foi a caracterização e formas de utilização das TIC na área Ciências da Natureza da escola analisada. 
Nesse sentido, a pesquisa contou com dois momentos. $O$ primeiro momento constituiu-se em uma análise documental do projeto político-pedagógico, junto com observações diretas realizadas no local. Já o segundo momento foi a análise dos questionários. Cabe ressaltar que na elaboração do questionário levou-se em consideração aspectos como: gênero, idade, curso de graduação, utilização das TIC, se há incentivo da gestão escolar na utilização destas e de que maneira isso ocorre e também quais as vantagens e desvantagens percebidas pelos professores em relação à utilização dos recursos tecnológicos no processo pedagógico escolar.

Responderam ao questionário sete mulheres e um homem com faixa etária entre 26 a 40 anos. Destes quatro possuem graduação em Ciências Biológicas, três em Física e um em Matemática.

Outro questionamento feito ao pesquisado foi de como ele percebe o uso das tecnologias digitais na escola: estes responderam que há uma grande influência destas no meio escolar, principalmente em relação ao uso de celulares, computadores, o uso da wi fi.

Em relação à utilização das tecnologias foram feitos os seguintes questionamentos: na escola existem laboratórios de informática adequados ao aprendizado? Utiliza as novas tecnologias em sala de aula e quais os recursos utilizados? Sentem-se capacitados a utilizar os recursos tecnológicos? Todas as respostas foram afirmativas referente a existência do laboratório de informática, porém, não há computadores suficientes para todos os estudantes e muitas vezes não há o acesso à internet. Sobre o questionamento se utilizam ou não as tecnologias em sala de aula a maioria respondeu que muito raramente, pois não se sentiam capacitados, principalmente porque o assunto requer constante atualização. Quanto à capacitação apenas um professor respondeu sentir-se capacitado, pois procura estar mais em contato com as tecnologias, visto que os estudantes conhecem muito a respeito e diz que tê-los como companheiros neste processo é fundamental para uma boa aprendizagem. Outro professor enfatizou que em parte se sente preparado, porém dá mais atenção aos recursos voltados para a sua área de atuação.

Referente aos recursos tecnológicos utilizados em sala de aula os resultados são mostrados na figura 1: pelos dados percebe-se que o computador, $29 \%$, e o projetor de multimídia, $28 \%$, são os mais utilizados. 
Gráfico 1 -

Recursos tecnológicos utilizados.

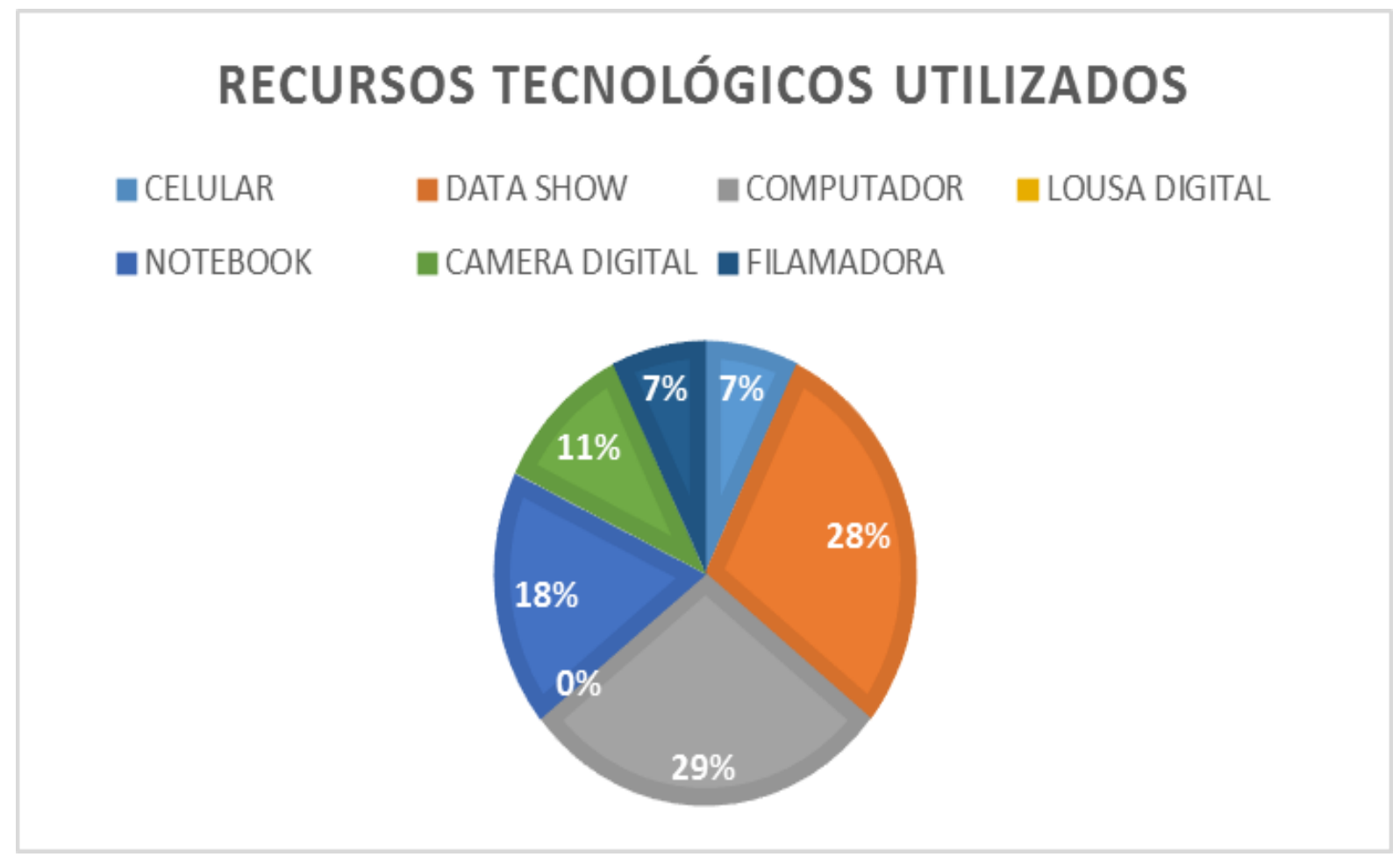

Fonte: elaborado pela autora.

No que diz respeito à gestão escolar os pesquisados foram questionados se há ou não o incentivo para a utilização da sala de informática e as novas tecnologias e de que maneira estes têm colaborado para que haja a integração e utilização de novas tecnologias da informação e comunicação. Nestes dois pontos todos os entrevistados informaram que há incentivo e as maneiras destacadas foram a disponibilização dos recursos audiovisuais - televisão, notebook, projetor de multimídia, filmadora, câmera digital -, sala de informática, um jornal online de responsabilidade do Grêmio Estudantil. Porém, também destacaram que a lousa digital não é utilizada, pois não há um espaço adequado e nem treinamento para a utilização do mesmo.

\section{Considerações finais}

No que se refere às tecnologias, ao analisar o projeto político-pedagógico da escola, observou-se que há uma preocupação com o uso das TIC e que estas devem estar inseridas no ensino e aprendizagem dos estudantes com vistas às transformações que ocorrem no meio social em que se encontra a escola.

Pode-se observar que a atuação da gestão escolar desempenha um papel fundamental para o uso das tecnologias. A infra-estrutura está presente na escola com computadores, lousa digital, tablets, projetor de multimída, internet. 
Com relação ao uso da internet destaca-se o problema do acesso, pois muitas vezes ela é lenta, o que dificulta os trabalhos. Grande parte dos professores utiliza internet para uso pessoal e para o preparo de materiais a serem utilizados em sala de aula.

Ficou evidente, nesta escola, que os professores precisam melhorar a implantação do uso das tecnologias em sala de aula. Embora a pesquisa não formule questões a respeito do por que do não uso, sabe-se que a formação e a sensibilização podem ser fatores de ações que a equipe gestora poderá intensificar.

\section{Referências}

BRASIL. Lei n. 9.394 de 20 de dezembro de 1996: estabelece as diretrizes e bases da educação nacional. Brasília: Diário Oficial da União, n. 248, 1996.

BRASIL. Estudos sobre a regulamentação da base curricular nacional e a organização do ensino médio encaminhado ao Conselho Nacional de Educação em 7 de julho de 1997. Brasília: MEC, 1997.

BRASIL. Pesquisa nacional qualidade da educação: a escola pública na opinião dos pais. Brasília: MEC, 2005.

BRASIL. Parâmetros curriculares nacionais para o ensino médio. Brasília: MEC/Semtec, 1999.

BRASIL. Relatório pedagógico do Enem 2001. Brasília: MEC/Inep, 2001.

CASTELLS, Manuel. A sociedade em rede. São Paulo: Paz e Terra, 1999.

FREIRE, Isa Maria. Janelas da cultura local: abrindo oportunidades para inclusão digital. Ciência da Informação, Brasília, v. 35, n. 3, 2006, p. 227-235.

MARTINS, Gilberto de Andrade. Estudo de caso: uma estratégia de pesquisa. São Paulo: Atlas, 2008.

SALES, Mary Valda Souza; VALENTE, Vânia Rita; ARAGÃO, Cláudia. Educação e tecnologias da informação e comunicação. Salvador: Uneb, 2010.

Marcia Melchior é licenciada em Química e especialista em Gestão Educacional pela Universidade Federal de Santa Maria.

Endereço: Av. Roraima, 1000 - 97105-900 - Santa Maria - RS - Brasil.

E-mail: marciamelchiormm@gmail.com.

Elena Maria Mallmann é professora no Programa de Pós-Graduação em Educação na Universidade Federal de Santa Maria, doutora em Educação pela Universidade Federal de Santa Catarina.

Endereço: Av. Roraima, 1000 - 97105-900 - Santa Maria - RS - Brasil.

E-mail: elena.ufsm@gmail.com.

Recebido em 16 de abril de 2016.

Aceito em 3 de junho de 2016. 